\title{
Effects of Gas Flaring On Surface and Ground Water in Irri Town and Environs, Niger-Delta, Nigeria
}

\author{
K. Emumejaye \\ Science Laboratory Technology Department Delta State Polytechnic, Ozoro,Nigeria
}

\begin{abstract}
Surface and ground water samples from gas flared area of Irri town and environs where gas flaring activities take place were analyzed for their heavy metals and trace element constituents and some physical characteristics. The results were evaluated with a view to determine and compare the quality and portability of the water from areas of high gas flaring activities with samples from areas of minimal gas flaring. The range of concentration of heavy metals were lead $(0.181-0.245 \mathrm{mg} / \mathrm{l})$, copper $(0.000$ to $0.007 \mathrm{mg} / \mathrm{l})$ Zinc $(0.001$ to $019 \mathrm{gm} / \mathrm{l})$, Nickel $(0.1-0.13 \mathrm{mg} / \mathrm{l})$, iron $(0.02-1.42 \mathrm{mg} / \mathrm{l})$ manganese $(0.008-0.032 \mathrm{mg} / \mathrm{l})$ cadmium $(0.000)$. Some of these concentration levels are above World Health Organization (WHO) maximum permissible limits, the general results showed that water in the study area had acceptable quality for household utilization except the ones that contain excess lead and iron which may require treatment.
\end{abstract}

Keywords: WHO,Gas Flaring, Surface Water, Groundwater, Niger-Delta

\section{Introduction}

The presence of unacceptable levels of foreign gaseous and particulate matters in the atmosphere is referred to as air pollution [18]. The deterioration of the environmental quality, which began when man first collected into villages and utilize fire has existed as a serious problem under the ever increasing impacts of exponentially increasing population and industrial society environmental contamination of air, water, soil and food has become a threat to continue existence of many plant and animal communities of ecosystem and ultimately threatens the very survival of the human race. Gas being flared into the atmosphere is one of such indiscriminate discharge. Petroleum industry operation is characterized by sets of hazards $[3,4,5,14]$. The nature and magnitude of these hazards are dependent on series of factors and varies significantly from one sector to another.

While it is true that Niger-Delta State of Nigeria suffers a great deal of immediate impact of gas flaring. It is now increasingly recognized that the contribution of the petroleum industry to the environment degradation goes beyond the immediate vicinity of the oil producing areas. The Nigeria Oil fields in the Niger - Delta Area produce about two millions barrels per day of oil and most of this oil comes from reservoir containing gas, which is produced with the oil $[6,7,13]$. This associated gas, a byproduct of the country's lifeline petroleum exploration activities is separated from the oil at the flow state and more than $95 \%$ of it flared. Currently a total sum of two billion standard cubic feet per day ( $\mathrm{SCF} /$ day), which is estimated to be about a quarter of the world gas flared [14]. The impact of gas flared is of local and global concern. The main components of this flare include carbon (iv) oxide $\left(\mathrm{CO}_{2}\right)$, methane $\left(\mathrm{CH}_{4}\right)$, nitrous oxide $\left(\mathrm{No}_{2}\right)$, water vapor and sulphur dioxide $\left(\mathrm{SO}_{2}\right)$. It is estimated that the Nigerian gas flared gas released 35 millions tons of carbon dioxide and 12 millions tons of methane in a year.

Since the discovery of oil in Nigeria, Niger- Delta region at Oloibiri of Bayelsa State in 1956, gas has been constantly flared. These result from the activities of the oil industries in the cause of the exploitation of crude oil or natural gas.

Gas flaring is therefore defined as the burning of natural gas and other petroleum hydrocarbons at flare site in the oil field and refineries during operations $[9,20]$.

\section{Gas Flaring In Nigeria}

Our country is endowed with significant oil and even more gas reserves. Gas flaring in Nigeria is as old as oil production. The flaring has contributed more green house gases to the earth than all other source, yet it is not being used as a fuel. Nobody benefit from the energy it contains. Local people complain about the rearing noise and the intense heat from the flares. They live and work alongside the flares with no protection [19]. Generally, flaring was made illegal under regulations in 1984 and only allowed in specific circumstances on a field by field basis. Lately the deadline was moved from 2005 to 2010. Gas flares have potentially harmful effects on the health and livelihood of the communities in their vicinity as they release a variety of poisonous chemicals such as nitrogen dioxide, sulphur IV oxide, volatile organic compounds (benzene, hydrogen sulphide) and carcinogens. Human beings exposed to such chemicals can suffer from a variety of respiratory problems, aggregated asthma, dysentery, chronic bronchitis as well as breathing difficulties and pains $[2,16,17,20]$. 


\section{Methodology And Sampling Techniques \\ Description of Study Area}

Irri is situated in Isoko South Local Government Area of Delta State. Irri is one of the oil producing communities in Delta State with several oil wells. The people are mainly Isokos. They are industrious and hardworking. They indulge in farming, rubber tapping, petting trading etc. they are hospitable and receptive to all people.

The study area lies within the Niger Delta sedimentary basin which is characterized by both Marine and mixed continental quaternary sediments that are composed of abandoned beach ridges and mangrove swamps [2]. The area is bounded by latitude $5^{\circ} 28^{\prime} 0^{\prime \prime}$ North and longitude $6^{0} 12^{\prime} 0^{\prime \prime}$ East in this pattern, world $>$ Africa $>$ Nigeria > Delta > Isoko South > Irri geographical co-ordinate. The area experience wet and dry season which are typical seasons in Nigeria $[14,15]$.

\section{Data Collection}

Samples of water were collected from around and within the flare site in the month of June 2012. Rainwater (directly from the sky), borehole water and surface water from a stagnant pool. Also samples of rain water, borehole and surface water were collected from irri environ where no gas flaring activities is evident. The samples were collected in clean plastic bottles and taken to the laboratory for analysis. To ensure that no foreign substance was introduced into the sample, the plastic containers were washed with the samples before final collection. Sample were analysized after 48 hours of collection. Results were compared with the World Health Organization limit values.

\section{Sampling Techniques}

This is the method for the rapid determination of $\mathrm{Pb}, \mathrm{Cu}, \mathrm{Zn}, \mathrm{Ni}, \mathrm{Cd}, \mathrm{Fe}$ and $\mathrm{Mn}$ in water samples using AA. This method is suitable for both dissolved and total metals in water and wastewater samples.

\section{Principle}

The sample was first aspired into the flame or electrothermal device where it was vaporized and atomized, radiation of the proper wavelength was then passed through the vapour containing the ground state atoms of the metal where absorption occurs. The magnitude of the AAS absorption signal was directly proportional to the concentration of the analyze metal in the sample solution.

\section{Apparatus and Reagents}

The apparatus and reagents used include: Unicam 929 AA Spectrometer,(AAS) 100mg/l stock standard solution of $\mathrm{Pb}, \mathrm{Cu}, \mathrm{Zn}, \mathrm{Ni}, \mathrm{Cd}, \mathrm{Fe}$ and $\mathrm{Mn}$ Conc $\mathrm{HNO}_{3}$ Hot Plate, Volumetric flask, Distill water, Beaker.

\section{Procedures}

Sample preparation for turbid and waste water A representative portion of the well mixed sample $(100 \mathrm{ml})$ was transferred into a beaker and $5 \mathrm{ml}$ of conc. $\mathrm{HNO}_{3}$ was then added.

The solution was evaporated to near dryness on a hot plate, making sure that the sample does not boil.

A gentle refluxing action of the solution was set by increasing the temperature of the hot plate. Heating was continued with addition of acid as necessary until digestion was completed (light coloured residue was obtained).

The beaker was allowed to cool and another $5 \mathrm{ml}$ of Conc. $\mathrm{HNO}_{3}$ was added. The beaker was covered with a watch glass and returned to the hot plate.

1.2ml Conc. $\mathrm{HNO}_{3}$ was then added to dissolve the residue. The residue was washed with distilled water and filtered to remove silicate and other insoluble material. The volume of the solution was adjusted to $100 \mathrm{ml}$ in a volumetric flask. A reagent blank determination was carried out, samples and reagent blank was analyzed for total heavy metals with the flame AAS.

\section{Sample Preparation for Surface Ground Water Samples}

Samples were not pretreated in any way they were analyzed directly using the AA.

\section{Calibration and Analysis}

Single elemental working standard solutions were prepared by dilution of $1000 \mathrm{mg} / \mathrm{l}$ stock solutions of the individual elements ( $\mathrm{Pb}, \mathrm{Fe}, \mathrm{Cu}, \mathrm{Zn}, \mathrm{Ni}, \mathrm{Cd}$ and $\mathrm{Mn})$.

A minimum of five standard working solution were prepared daily from the stock solution. The solutions ranged between $0.1 \mathrm{mg} / \mathrm{l}$ to $10.0 \mathrm{mg} / \mathrm{l}$. External calibration was used by running de-ionized Water and a suite of calibration curve were then generated for each metal.

The extraction solution and blank were then run on the AA to obtain the absorbance values. 
Effects Of Gas Flaring On Surface And Ground Water In Irri Town And Environs, Niger-Delta,

Concentrations of the metals in the water sample were then calculated from the equation of the calibration curve. The concentration level of the constituents were compared with the WHO [24] recommended standards.

\section{Calculations}

Conc. Of Element $\mathrm{x}(\mathrm{mg} / \mathrm{l})=\mathrm{A}-\mathrm{B}$

Where, $\mathrm{A}=$ Conc. Of Element $\mathrm{x}(\mathrm{mg} / \mathrm{l}), \mathrm{B}=$ conc. of blank (mg/l)

\section{Result}

\section{Result And Discussion}

The analytical results obtained in the research work and the World Health Organization WHO $[23,24]$ stands for portable rain, surface and borehole water are presented in the tables below:

Table1: Sample Site 1-Physiochemical parameters results Obtained from Gas Flaring site

\begin{tabular}{|c|c|c|c|c|}
\hline Parameter & Surface water & Rain water & $\begin{array}{l}\text { Borehole } \\
\text { water }\end{array}$ & $\begin{array}{l}\text { WHO Standard } \\
\text { maximum limit }\end{array}$ \\
\hline $\mathrm{PH}$ & 6.76 & 6.80 & 6.47 & $6.5-8.5$ \\
\hline Alkalinity(mg/l) & 16.00 & 20.00 & 14.00 & 500 \\
\hline $\begin{array}{l}\text { Conductivity } \\
(\mathrm{mg} / \mathrm{l})\end{array}$ & 7.00 & 22.20 & 60.00 & - \\
\hline Colour $(\mathrm{Hu})$ & 11.00 & 14.00 & 10.00 & $15.0-85.0$ \\
\hline Hardness (mg/l) & 24.20 & 17.70 & 18.45 & 500 \\
\hline Temperature $\left({ }^{0} \mathrm{c}\right)$ & 30.90 & 30.10 & 29.60 & - \\
\hline TDS (mg/l) & 6.75 & 15.24 & 19.34 & 1000.0 \\
\hline Turbidity (NTU) & 5.00 & 5.10 & 5.20 & 25 \\
\hline
\end{tabular}

Table2: Sample Site 2-Physiochemical parameters results Obtained from Irri Environs with Minimal Gas Flaring Activities

\begin{tabular}{|l|l|l|l|l|}
\hline Parameter & Surface water & Rain water & $\begin{array}{l}\text { Borehole } \\
\text { water }\end{array}$ & $\begin{array}{l}\text { WHO Standard } \\
\text { maximum limit }\end{array}$ \\
\hline PH & 6.40 & 5.50 & 6.45 & $6.5-8.5$ \\
\hline Alkalinity $(\mathrm{mg} / \mathrm{l})$ & 7.00 & 10.40 & 6.00 & 500 \\
\hline Conductivity $(\mathrm{mg} / \mathrm{l})$ & 17.00 & 20.00 & 18.40 & - \\
\hline Colour $(\mathrm{Hu})$ & 34.00 & 31.00 & 29.50 & $15.0-85.0$ \\
\hline Hardness $(\mathrm{mg} / \mathrm{l})$ & 35.50 & 37.00 & 34.40 & 500 \\
\hline Temperature $\left({ }^{\mathrm{c}} \mathrm{c}\right)$ & 30.00 & 29.00 & 30.10 & - \\
\hline TDS $(\mathrm{mg} / \mathrm{l})$ & 78.10 & 6.20 & 7.80 & 1000.0 \\
\hline Turbidity $(\mathrm{NTU})$ & 5.00 & 4.60 & 5.00 & 25 \\
\hline
\end{tabular}

Table3: Sample Site1- results obtained around the flare site

\begin{tabular}{|l|l|l|l|l|l|l|}
\hline S/N & Standard methods & \multicolumn{1}{|c|}{$\mathbf{1}$} & \multicolumn{1}{|c|}{$\mathbf{2}$} & \multicolumn{1}{|c|}{$\mathbf{3}$} & Mean & $\begin{array}{l}\text { (mg/l) } \\
\text { WHO } \\
\text { limits } \\
(\mathbf{2 0 0 7})\end{array}$ \\
\hline $\begin{array}{l}\text { Sample } \\
\text { I.D }\end{array}$ & & $\begin{array}{c}\text { Surface } \\
(\mathrm{mg} / \mathrm{l})\end{array}$ & Rain $(\mathrm{mg} / \mathrm{l})$ & $\begin{array}{c}\text { Borehole } \\
(\mathrm{mg} / \mathrm{l})\end{array}$ & & \\
\hline $\mathrm{Pd}$ & ASTMD3559-96 & $\mathbf{0 . 1 9 5}$ & $\mathbf{0 . 2 4 5}$ & $\mathbf{0 . 1 8 1}$ & 0.207 & 0.05 \\
\hline $\mathrm{Cu}$ & ASTMDI688 -95 & 0.007 & 0.007 & $\mathrm{ND}$ & 0.007 & 1.5 \\
\hline $\mathrm{Zn}$ & ASTMDI691-95 & 0.002 & 0.019 & 0.001 & 0.0073 & 5 \\
\hline $\mathrm{Ni}$ & ASTMDI1886-94 & 0.07 & 0.1 & 0.13 & 0.1 & $\mathrm{~N} / \mathrm{A}$ \\
\hline $\mathrm{Fe}$ & ASTMDI068 -95 & 0.08 & 0.02 & $\mathbf{1 . 4 2}$ & 0.507 & 1.0 \\
\hline $\mathrm{Mn}$ & ASTMD858 -95 & 0.029 & 0.008 & 0.032 & 0.023 & 0.5 \\
\hline $\mathrm{Cd}$ & ASTMD355795 & $\mathrm{ND}$ & $\mathrm{ND}$ & $\mathrm{ND}$ & $\mathrm{ND}$ & 0.005 \\
\hline
\end{tabular}

$\mathrm{N} / \mathrm{A}=$ Not Available, $\mathrm{ND}=\quad$ Not Detected

Note: The results obtained complied with WHO limit except those highlighted on bold. 
Table 4: Sample Site 2 - Results Obtained from Irri Environs with Minimal Gas Flaring Activities

\begin{tabular}{|c|c|c|c|c|c|c|}
\hline $\mathbf{S} / \mathbf{N}$ & $\begin{array}{l}\text { Standard } \\
\text { methods }\end{array}$ & 1 & 2 & 3 & Mean & $\begin{array}{l}(\mathrm{mg} / \mathrm{l}) \\
\text { WHO } \\
\text { limits } \\
(2007)\end{array}$ \\
\hline $\begin{array}{l}\text { Sample } \\
\text { I.D }\end{array}$ & & $\begin{array}{c}\text { Surface } \\
(\mathrm{mg} / \mathrm{l})\end{array}$ & Rain (mg/l) & Tap (mg/l) & & \\
\hline $\mathrm{Pd}$ & ASTMD3559-96 & 0.005 & 0.004 & 0.001 & 0.003 & 0.05 \\
\hline $\mathrm{Cu}$ & ASTMDI688-95 & 0.006 & 0.007 & ND & 0.004 & 1.0 \\
\hline $\mathrm{Zn}$ & ASTMDI691 - 95 & 0.002 & 0.018 & 0.001 & 0.007 & 5 \\
\hline $\mathrm{Ni}$ & ASTMDI1886-94 & 0.08 & 0.1 & 0.14 & 0.107 & N/A \\
\hline $\mathrm{Fe}$ & ASTMDI068 - 95 & 0.08 & 0.02 & 0.22 & 0.107 & 0.3 \\
\hline $\mathrm{Mn}$ & ASTMD858-95 & 0.029 & 0.008 & 0.032 & 0.023 & 0.5 \\
\hline $\mathrm{Cd}$ & ASTMD355795 & ND & ND & ND & ND & 0.005 \\
\hline
\end{tabular}

$\mathrm{N} / \mathrm{A}=$ Not Available, ND $=\quad$ Not Detected

\section{Discussion}

WHO [23,24] set the maximum permissible limits of heavy metals in our waters as follow: lead $\left(0.05 \mathrm{mgl}^{-1}\right)$, copper $\left(1.0 \mathrm{mgl}^{-1}\right)$, zinc $\left(5.0 \mathrm{mgl}^{-1}\right)$, iron $\left(0.3 \mathrm{mgl}^{-1}\right)$ manganese $\left(0.1 \mathrm{mgl}^{-1}\right)$ cadmium $\left(0.005 \mathrm{mgl}^{-1}\right) \mathrm{with}^{-}$ the exception of lead and iron, all the water samples analyzed in this project were fully within these limits and therefore posed no danger to consumers as these specific heavy metals are concerned. For lead the surface, Rain and Tap water samples did not meet the WHO guideline value.

\section{Conclusion and Recommendations}

From the study, it is seem that gas flaring has untold effect on the environment especially in the study area which ranges from its effect on the waters to its effect in the atmosphere. For instance, high lead and iron content of the substance, high lead and iron content of the waters has been raced to gas flaring in the study area. Based on the results from the research work:

- It will be advantageous to utilize this gas alternatively either by expressing it to generate revenue or for other domestic uses to improve the standard of living in this our blessed country Nigeria. By so doing gas is seen as another service of fuel as this will go a long way to save our environment from pollution. This will also help to reduce its effect on human and animal beings.

- The promulgation of the associated gas re-injection of Nigeria which requires companies to stop flaring. This represents a regulative responses to the degradation of environment and the Niger-Delta which the study area is conduced as being caused by gas flaring the amendment of the said decree in 1955 by fixing a rate of 2 kobo as penalty for each thousand cubic of gas flared in a gross manifestation of the fact that environments have been ineffective legislation and enforcement of a more reasonable amount of N10, 000 penalty for each thousand cubic feet of gas flared as this will go a long way to reduce the rate of gas flaring.

- The government and companies should provide relief assistance to the communities involved in the study area as regards to provision of potable water treatment plants to enable them reduce the effects on their waters. Compensation and huge attention in terms of medical care should be paid to the host communities.

\section{References}

[1] Allen, C.K (1999), A New Geographic of Nigeria LongmanPublishing 65ff

[2] Anoliefo. G.O (1991), Forcados Blend crude oil effects in Respiratory mechanism, mineral element composition and growth of citrulus vulgaris school unpublished doctoral thesis, university of Benin.

[3] Balogun, A.C (2008) Arematics in Private Water Supplies in Warri, Delta State Nigeria Scientia Afr. (7) 1: 74-80.

[4] Browen, M. (2007). The price of oil Human Rights watch.

[5] Canadian Council of ministers of the environment lands and parks (1992). Toxicology of Copper, Lead and ChromiumCCCME (2001) Canadian Water Quality Guidelines for the Environment and Human Health.

[6] Cooper, D.c, Neal Al, Kuikadapcl, RK, Brewe \& Coby Aipicardal, FW (2005). Effects of sediment Iron Mineral Composition on Microbial Mediated Changes in Divalent Metal Speciation.

[7] Davies, BC (1995), Lead in heavy metals in waters. Second edition (B. Alloway ied>) Blackie, New York, PP 206 - 223.

[8] Drill, S, et al: The environment lead problem. An Assessment of lead in soil forms a multimedia perspective. Washington DC, Usenvironmental protection Agency 1979.

[9] (FFS, 2005): Environmental fact sheet lead. Health information Summary. New Hampshire department of environmental services ARD, ENP - 9 www.des.nh.gov

[10] Ehirim, CN, Nwankwo CN (2010). Evaluation of Aquifer Characteristics and Ground Water Quality using Geoelectrio Method in Globa. Part Harcourt Archives of Apple.Sci Res 2 (2). 296 - 403.

[11] Environmental Health Criteria for Cadmium Goneva World Health Organization, 1979 (Interim Report).

[12] Environmental Impacts and Economical analysis of gas flaring in the Niger- Delta (2008). 
[13] Federal Environmental Protection Agency (F.E.P.A.) (1991). Guidelines and standards for environmental pollution control in Nigeria.

[14] Eteng Inya A., (1997). The Nigerian State, Oil Exploration and Community Interest: Issues and Perspectives. University of Port Harcourt, Nigeria conf paper

[15] Etu - Efeotor J.O (1998). Hydrochemical analysis of surface andground waters of Gwagwalada area of central Nigeria. Globa J Pure Appl. Sci - 4 (2): 153 - 163.

[16] Joseph, F.S (2001) Heavy metal poisoning Wassan WL Medical Library Thomson PP 66-69.

[17] Marcus, S (2001): Toxicity of lead Wasson WL Medical LibraryThomson PP 76-77.

[18] Ogban, F E Emoyan, O O And Akarah, E(2006). Evaluation of Heavy Metals Loading of River Ijana in Ekpan - Warri, Nigeria. J. Appl. Sci. Environ. Mgt.Vol. 10 (2) 121 - 127

[19] Okizie, D.V. et al (1989): Flaring of Associated Gas in Oil Industry.

[20] Ojeifo SN (2009). Gas flaring in Nigeria and its impact on the environment. Robinson publ. press, Lagos Nig. pp 24-28.

[21] Olobaniyi, S.B, Efe S.I (2007), Comparative Assessment of Rain Water and Ground Water Quality in an Oil Producing Area of Nigeria Environmental Health and Gas Res. (6)2: 111 -118.

[22] Ushie FA, Amadi PA (2008). Chemical characteristics of groundwater from parts of the basement complex of Oban Massif and Obudu Plateau, south eastern Nigeria. Sci. Afr. 7(2): 81-88.

[23] World Health Organization WHO (1996) Guideline for drinking water quality, health criteria and other supporting information Geneva.

[24] World Health Organization, WHO (2007). International Drinking Water Standards. $3^{\text {rd }}$ edition. 